\title{
Analysis of the Internal Flow Structure of Torque Converter Using Proper Orthogonal Decomposition under Transient Driving Conditions
}

\author{
Yasunori Kunisaki ${ }^{1)}$ Shigeru Murata ${ }^{2)}$ Yohsuke Tanaka ${ }^{2)}$ \\ 1) Graduate School of Engineering, Kyoto Institute of Technology, Matsugasaki, Sakyo-ku, Kyoto 606-8585, Japan \\ EXEDY Corporation, 1-1-1, Kidamotomiya, Neyagawa-shi, Osaka, 572-8570, Japan (E-mail: y-kunisaki@exedy.com) \\ 2) Faculty of Mechanical Engineering, Kyoto Institute of Technology, Matsugasaki, Sakyo-ku, Kyoto 606-8585, Japan
}

Received on October, 10, 2020

\begin{abstract}
The characteristic structure of the flow field in a torque converter is quantitatively evaluated using proper orthogonal decomposition (POD) under transient driving conditions assuming start-up acceleration and deceleration of a vehicle. The time-series velocity data inside the torque converter to be input to POD is measured using a particle image velocimetry (PIV) technique. At first, in the case of changing the rotational speed of the impeller or turbine, dynamic cascades with changing rotational speed were observed to induce fluid motion. The flow field structure was gradually reformed according to the speed ratio after transition. In addition, the region of structural changes of the flow field was found to be larger for the decelerating driving condition compared to the case of start-up acceleration.
\end{abstract}

KEY WORDS: power transmission, automatic transmission, measurement/torque converter, PIV, POD, transient [A2]

\section{Introduction}

It is well known that the automotive torque converter is one of the most important components in an automotive transmission. The torque converter consists of three elements: an impeller, a turbine, and a stator. The torque converter has several basic functions. The functions of creep starting and continuous speed variation provide a smooth take-off and better acceleration performance. The damping function reduces the engine torque fluctuation, which decreases the noise and vibration of the drive train. Furthermore, since the transmission efficiency of an oildriven torque converter is less than that of a mechanical clutch system, the fuel consumption rate of vehicles that have an automatic transmission system is lower than vehicles having a manual transmission.

Recently, the need for lower fuel consumption and higher acceleration performance in vehicles is high considering both energy and environmental problems. The characteristics of the hydrodynamic performance of the torque converter significantly affect the above performances of vehicles. Furthermore, the demand for reduction of the axial dimensions of the powertrain is rapidly increasing in the design of the torque converter, for example, by changing the shape of the torque converter to an elliptic shape or by enlarging the spaces for the lock-up clutch and the damper. In order to satisfy these demands, it is necessary to optimally design the shape of the blades and the flow passages of the torque converter. Thus, it is necessary to understand the details of the fluid behavior in the flow passages.

The internal flow field of the torque converter is an unsteady flow field in which the cascades interfere with each other. For the flow field of the torque converter composed of a finite number of blades, the blade passing frequency depends on the number of blades and rotational speed of each cascade. The working oil fluid in the torque converter circulates through each cascade. Therefore, multiple frequencies overlap each other during circulation, and the frequency characteristics of the flow field become complicated. Furthermore, the characteristics of the frequency are changed by the rotating speed of each cascade according to the driving condition of the vehicle. In order to address problems such as noise and vibration, it is necessary to understand the frequency characteristics in detail. In addition, the internal flow field of the torque converter becomes more complicated because each cascade has various rotational speeds according to changes in the driving conditions, such as the acceleration or deceleration of the vehicle. Since the torque converter also has the function of a continuous reduction gear, it is necessary to analyze the internal flow structure not only in the steady condition but also in the transient condition, and to appropriately design the blade shape and flow path.

Computational fluid dynamics (CFD) has been widely used to understand the internal flow structure of the torque converter. Significant results of analysis for the flow field characteristics, such as separate flows and secondary flows, have been reported ${ }^{(1)}$ With the assistance of the most advanced computers, a report applying large eddy simulation (LES) to the internal flow of the torque converter has revealed that it is necessary to perform unsteady flow field analysis in order to understand the internal flow field ${ }^{(2)}$. However, the amount of data obtained from these analyses is enormous, and it is very difficult to clarify and evaluate the mechanism and the phenomena that are effective for designing the blade shape and flow passage of the torque converter. Therefore, there is a need for a method of investigating and analyzing the large amount of spatio-temporal data obtained from experimental and numerical analyses, and for extracting the potential characteristic structure in a short time. In recent years, in the field of fluid analysis, proper orthogonal decomposition (POD) has been used as a multidimensional time-series analysis method. Proper orthogonal decomposition is a method by which to extract 
Vol.11, No.4(2020)

the characteristic structure from spatio-temporal data obtained by experimental and numerical analyses. In addition, a method called snapshot POD that can obtain the POD mode with a small amount of calculation from the time-series data of a large-scale flow field (3-5) has been proposed. In the case of applying POD to the numerical analysis results for the flow field of the torque converter, the occurrence of a regular vortex structure is the main cause of energy loss in the flow field ${ }^{(6,7)}$. Nevertheless, the results obtained by CFD are limited in capability to show the actual flow phenomena of the torque converter with high accuracy, and validation of the results obtained by CFD is still strongly dependent on the results obtained by actual experiments. In terms of experimental analysis, a case study has also revealed that the phase-averaged velocity maps according to the relative angles of the cascade can be reconstructed to visualize the characteristics of this unsteady flow field ${ }^{(8)}$. There has also been a report that the effect of the stator on features of frequency characteristics can be confirmed by applying a wavelet transform ${ }^{(9)}$. However, these reports are limited to the analysis of steady-state driving conditions, and there are no reports investigating transient conditions as far as the authors know.

The objective of the present paper is to quantitatively analyze and evaluate the flow field structure in the torque converter using POD under transient driving conditions, such as the start-up acceleration or the deceleration of vehicle. The velocity field is measured using a particle image velocimetry (PIV) technique. A wavelet transform is applied to the time-series measured instantaneous flow field data in order to analyze the characteristics of the frequency for the internal flow field of a torque converter.

\section{Plexiglass torque converter and experimental apparatus}

\subsection{Plexiglass torque converter for visualization}

A 3D CAD model of the torque converter and a schematic diagram of the measurement region for visualization are shown in Fig. 1. The model is of one of our products, namely, a standard elliptic-type torque converter. The fundamental torque converter performance is as follows: the stall torque ratio is 1.7 , and the speed ratio of the coupling point is 0.75 . The torus consists of an impeller, a turbine, and a stator, which make up the fluid coupling part of the torque converter. The outer diameter of the torus and the flatness ratio are $241 \mathrm{~mm}$ and 0.55 , respectively. The number of blades for the impeller, turbine, and stator are 41, 37, and 35, respectively. The shape of the torque converter, such as the blade thickness, is partly modified in order to restrict the strength for use in a plexiglass model. Each part has been machined by a numerical control machine using a block of colorless transparent plexiglass and has been assembled after machining. In order to minimize the influences of refraction and scattering of the laser sheet, oil that has a refractive index (index reflection of oil: 1.5) that is nearly the same as that of the plexiglass (index of reflection: 1.49) was used. In the experiment, the temperature of the working oil is carefully controlled to $35 \pm 2^{\circ} \mathrm{C}$. In addition, in order to minimize the effects of the reflection of the wall curvature, the entire torque converter is submerged in a plexiglass box filled with the same oil, as shown in Fig. 1. The position of the measured cross-section is $X=91 \mathrm{~mm}$ on the inner circumference of the torus in which the stator is located.

\subsection{Particle image velocimetry measurement system}

A schematic diagram of the experimental setup is shown in Fig. 2. The setup consists of the transparent torque converter for visualization, the mechanical part used to hold and drive the torque converter, and the hydraulic circuit part used to circulate the working oil fluid. The mechanical part consists of an input motor used to drive the impeller of the torque converter and an output motor used to absorb turbine power. The torque of the input/output motor is transmitted to the input/output shaft with the torque converter through the timing belt. The angular position and torque of the impeller and turbine are detected by encoders and torque meters attached to the input shaft and the output shaft, respectively. The hydraulic circuit consists of a hydraulic pump, a tank, several pipes, and a torque converter. The working oil fluid flows into/out of the torque converter via the shaft, which is the same as in an actual hydraulic circuit. The temperature sensors are attached to the inlet and outlet pipes of the hydraulic circuit. The temperature of the working oil fluid is controlled by a heater and an air-cooling system, and measurement can be performed under a constant temperature condition.

The control equipment consists of a control panel, a function generator (IWATSU ELECTRIC, SG-4115), and a data logger (Graphtec, midi LOGGER HV GL2000, sampling frequency: $1,000 \mathrm{~Hz})$. The control panel controls the rotational speed and the working oil fluid pressure and processes the angle signal transmitted from the encoders placed on the input and output shafts. The function generator sends a trigger signal (TTL) in order to synchronize each device and controls the recording timing of a high-speed camera. Finally, a data logger records the trigger signal and angle signal.

The optical equipment for capturing the particle images
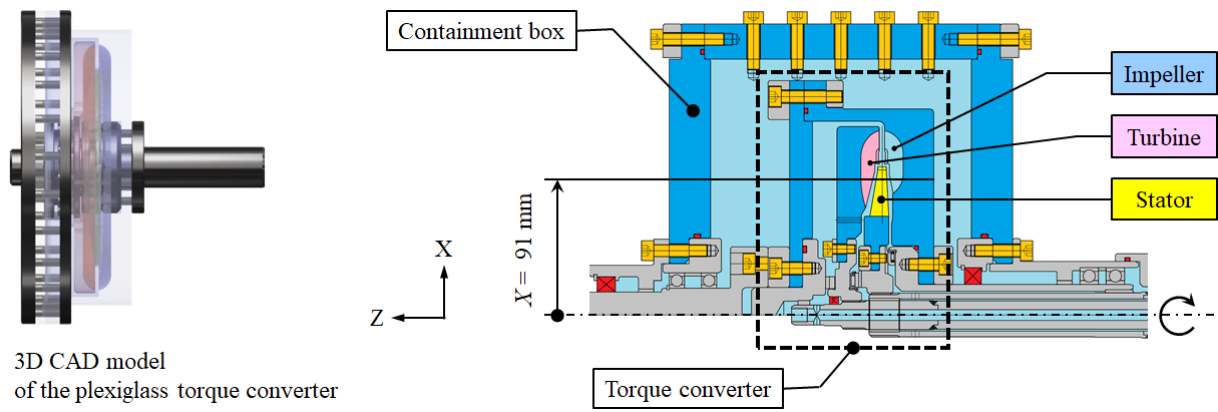

Fig. 1 Plexiglass torque converter and cross-section of the measurement region. 
consists of a continuous wave laser (Viasho, VA-II-N-532, power: $3 \mathrm{~W}$, wavelength: $532 \mathrm{~nm}$, thickness of the laser light sheet: approximately $2.0 \mathrm{~mm}$ ), and a high-speed camera (Photron, FASTCAM mini UX100, 1,280×800 pixels, dynamic range: 8 bits, time interval: $0.125 \mathrm{~ms}$ ). A continuous wave laser is used to supply a laser light sheet to illuminate the flow field. The laser light sheet is reflected by the mirror and illuminates the measurement region. The camera is used to capture the particle images. The specifications of the tracer particles used for visualization are as follows: material, nylon 12; average diameter, $50 \pm 0.2 \mu \mathrm{m}$; and specific gravity, 1.03 . The specifications of the working oil fluid used for visualization are as follows: oil type, silicone oil; specific gravity, 0.995; and kinematic viscosity coefficient, $15\left[\mathrm{~mm}^{2} / \mathrm{s}\right]$. Tracer particles having a specific gravity that is approximately the same as that of the working oil fluid were used in order to obtain better tracing ability. The resolution of the images obtained in this experiment was 0.05 [mm/pixel]. The obtained PIV images were divided into $32 \times 32$ pixel regions. In this case, the spatial resolution corresponds to $1.6 \mathrm{~mm} \times 1.6$ $\mathrm{mm}$. The average number of tracer particles appearing in each region was approximately 10 .

The direct cross-correlation method ${ }^{(10)}$, which is most widely used in many PIV studies concerned in fluid mechanics, was used for the calculation of the velocity vector. The correlation-based correction (CBC) technique ${ }^{(11)}$, in which the peak value of the cross-correlation coefficient becomes remarkable and an

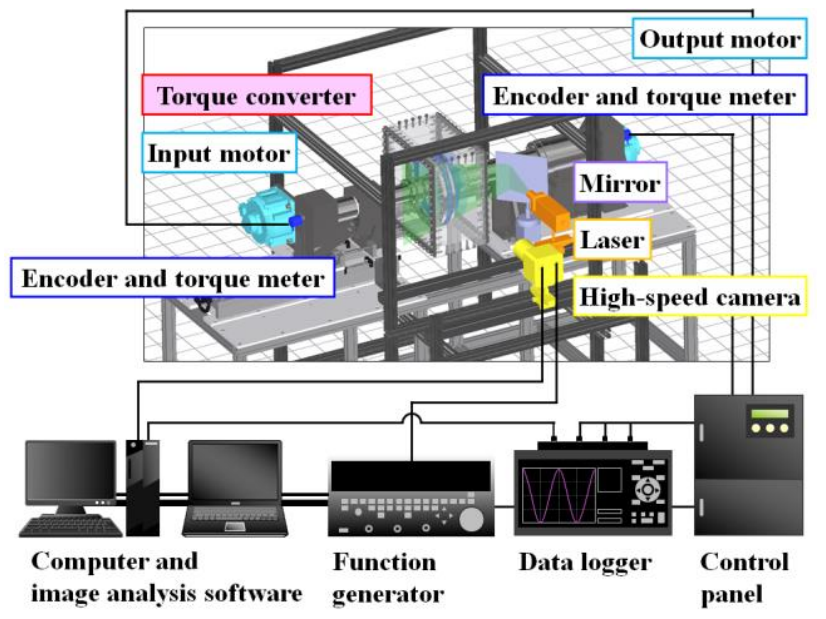

Fig. 2 Schematic diagram of the experimental setup. improved $\mathrm{S} / \mathrm{N}$ ratio is expected, was used in the image processing algorithm. Sub-pixel analysis by Gaussian distribution was used to obtain the velocity vectors with a sub-pixel-order measurement accuracy, and a statistical method was adopted to eliminate the erroneous vectors.

\subsection{Driving pattern for measurements}

In the present study, two driving patterns assuming the startup acceleration and the deceleration of vehicle are set as measurement conditions. The start-up acceleration is a driving pattern in which the rotational speed of the impeller connected to the engine increases by turning on the accelerator from the idling condition. The deceleration pattern is a pattern in which the rotational speed of the turbine connected to the vehicle decreases by braking from a steady driving condition. The schedule of each driving pattern is shown in Table 1 and Fig. 3. Here, the speed ratio is the ratio of the rotational speed of the turbine to the impeller. In Fig. 3, the light-blue, orange, and pink regions indicate the regions before the transition, during the transition, and after the transition, respectively. For reference, a representative Reynolds number under the steady-state driving

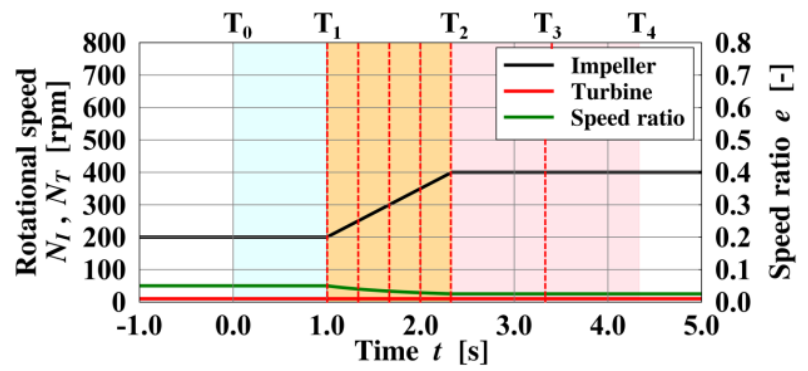

(a) Start-up acceleration driving pattern

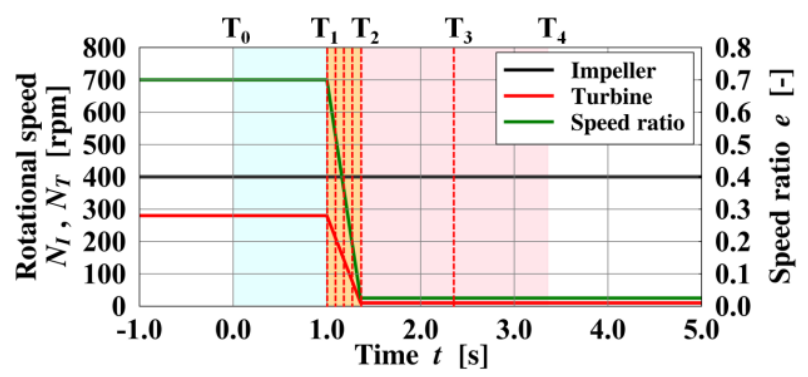

(b) Deceleration driving pattern

Fig. 3 Driving pattern for two different rotational speeds.

Table 1 Schedule of driving pattern for the start-up acceleration driving condition and deceleration driving condition.

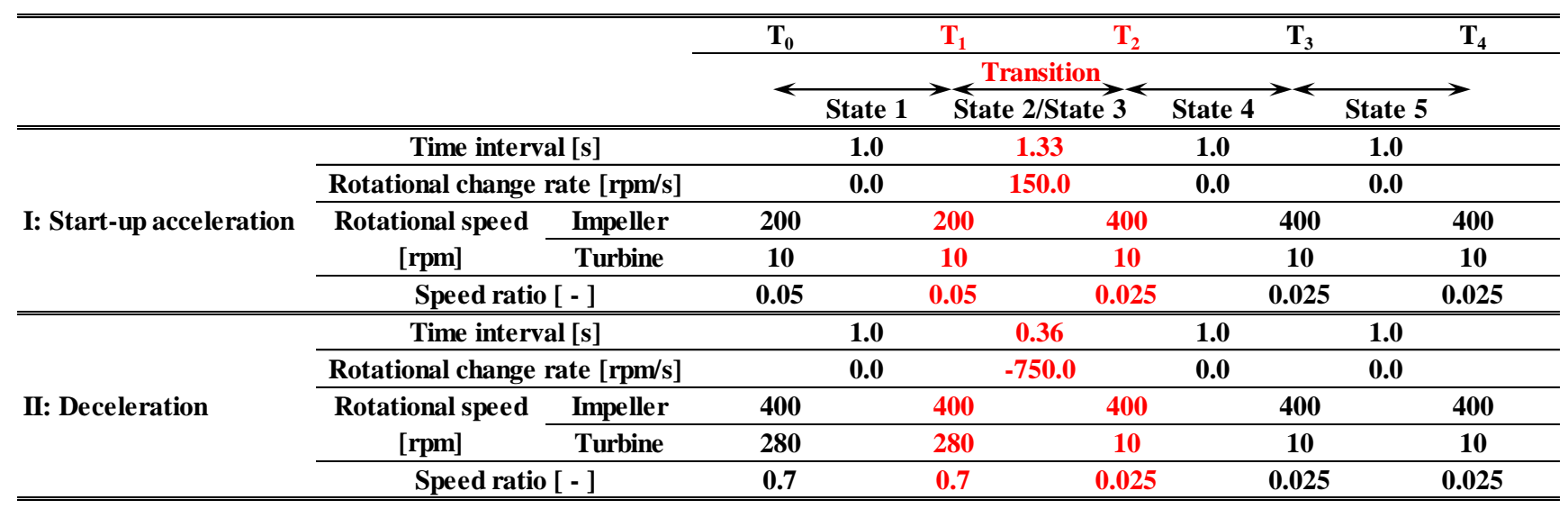


Vol.11, No.4(2020)

condition with an impeller rotational speed of $200 \mathrm{rpm}$ and a speed ratio of 0.1 was estimated to be $6 \times 10^{4}$ using the geometrically averaged radius of the flow passage, the mean flow velocity of the impeller outlet calculated from one-dimensional analysis, and the kinetic viscosity of the working fluid.

\subsection{Particle image velocimetry results}

Figures 4 and 5 show the distributions of velocity vectors and vorticity contours under the start-up acceleration pattern and deceleration pattern, respectively. For each pattern in Figs. 4 and 5 , the results show the instantaneous flow field at 1 second before the transition, during the transition, and 1 second after the transition. The time from the transition start time $\mathrm{T}_{1}$ to the transition end time $\mathrm{T}_{2}$ is divided into four periods. For the case in which the transition time is $\Delta T$, the times are $(0 / 4) \Delta T\left(=\mathrm{T}_{1}\right)$, (1/4) $\Delta T,(2 / 4) \Delta T,(3 / 4) \Delta T$, and (4/4) $\Delta T\left(=\mathrm{T}_{2}\right)$. The results at each time are shown in Figs. 4(b) though 4(h) and Figs. 5(b) through 5(h). In Figs. 4 and 5, the colors of the figure frames are light blue before transition, orange in transition, and pink after transition.

In Fig. 4(b), under the start-up acceleration pattern before the transition, clockwise circulation occurs on the pressure side of the stator blade. After the transition ends, the same circulation structure remains. The flow structures before and after the transition are similar, and, in Figs. 4(c) through 4(g), the magnitude of the vorticity increases as the rotation speed increases. In Fig. 5(b), under the deceleration pattern before the transition, the flow passes along the stator blade. However, clockwise circulation occurs on the pressure side of the stator, even after the transition has ended. The flow structures before and after the transition are different, and the magnitude of the vorticity increases. The structure of the flow field in the torque converter is mainly determined according to the speed ratio. Although in Fig.4,

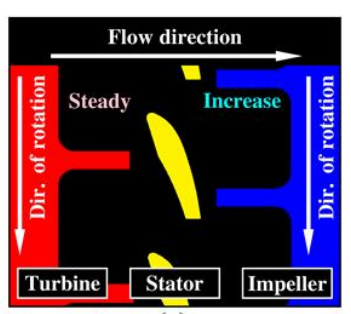

(a)

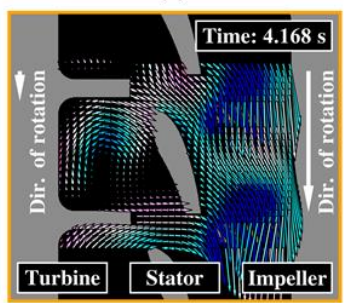

(e)

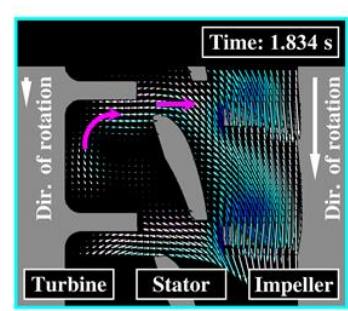

(b)

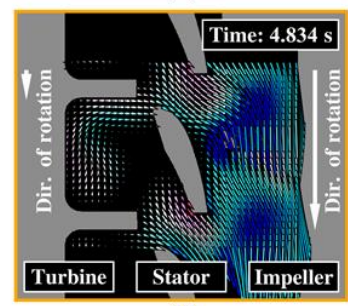

(f)

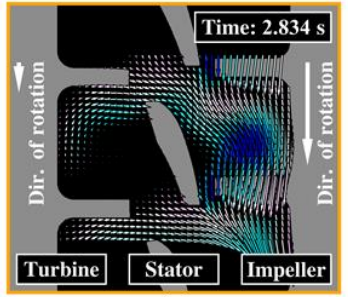

(c)

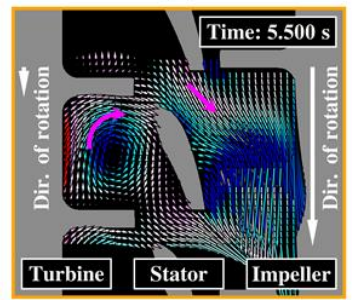

(g)

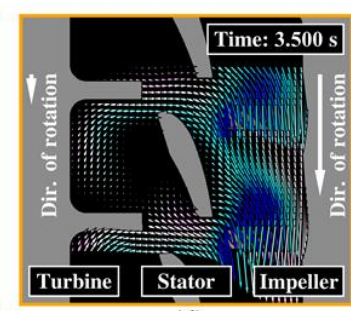

(d)

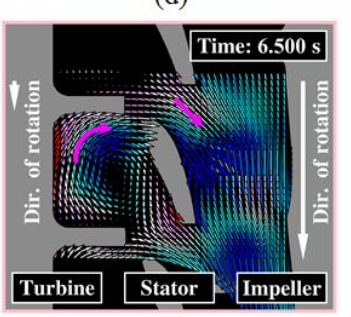

(h)

Fig. 4 Distributions of velocity vectors and vorticity contour under start-up acceleration driving pattern.

(a) Reference diagram, (b) Time: $\mathrm{T}_{0}$ before transition, (c) Time: $\mathrm{T}_{1}$ at start time of transition, (d) Time: $1 / 4 \Delta T$ in transition,

(e) Time: $2 / 4 \Delta T$ in transition, (f) Time: $3 / 4 \Delta T$ in transition, (g) Time: $\mathrm{T}_{2}$ at end time of transition,

(h) Time: $T_{3}$ after transition, where $\Delta T$ indicates the interval of transition time.

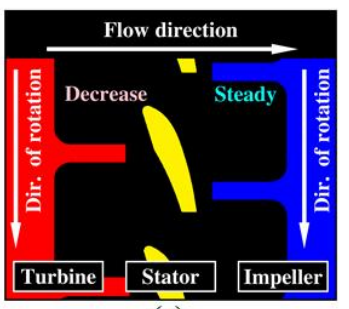

(a)

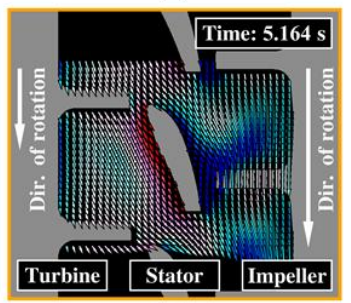

(e)

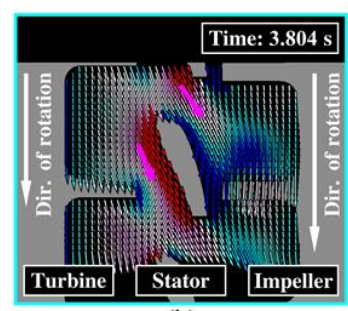

(b)

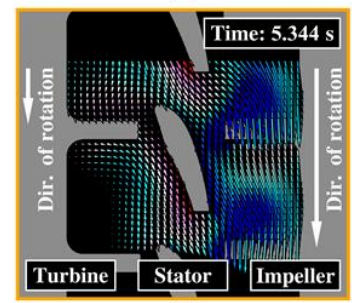

(f)

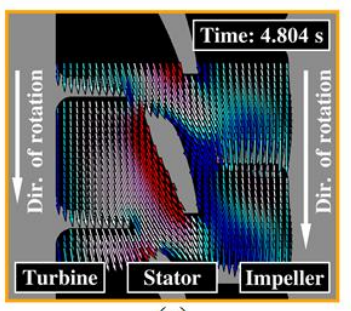

(c)

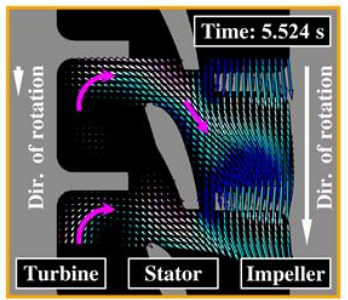

(g)

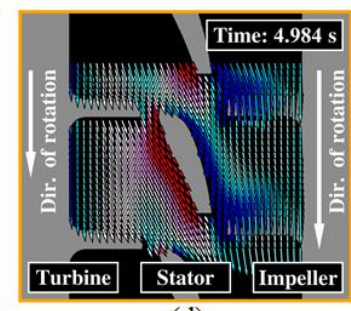

(d)

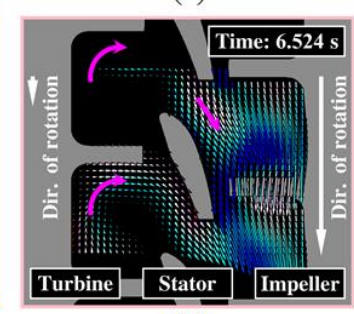

(h)

Fig. 5 Distributions of velocity vectors and vorticity contour under deceleration driving pattern.

(a) Reference diagram, (b) Time: $\mathrm{T}_{0}$ before transition, (c) Time: $\mathrm{T}_{1}$ at start time of transition, (d) Time: $1 / 4 \Delta T$ in transition,

(e) Time: $2 / 4 \Delta T$ in transition, (f) Time: $3 / 4 \Delta T$ in transition, (g) Time: $\mathrm{T}_{2}$ at end time of transition,

(h) Time: $T_{3}$ after transition, where $\Delta T$ indicates the interval of transition time. 
Vol.11, No.4(2020)

for the start-up acceleration pattern, the speed ratio changes little from 0.1 to 0.05 at a low speed ratio as the rotation speed changes, in Fig. 5, for the deceleration pattern, the speed ratio changes from 0.7 to 0.025 (from a high speed ratio to a low speed ratio). In other words, in Fig. 5, since the speed ratio changes greatly, the structure of the flow field also changes. As shown in Figs. 4 and 5 above, the change in the flow structure in the torque converter during the transition process can be quantitatively captured.

\subsection{Wavelet transform analysis}

The internal flow field of the torque converter with cascade interference is an unsteady flow. In order to design the blade shape of the torque converter, it is essential to understand not only the time-averaged flow field, but also the unsteady field. Furthermore, in the case of steady driving conditions, the frequency characteristics are dependent on the blade passing frequency ${ }^{(12)}$. However, in the case of the transient driving condition, the frequency characteristics are predicted to be more complicated. Fourier analysis is a method by which to analyze the frequency characteristics of unsteady phenomena. However, because of the loss of temporal information, this method is not suitable for a flow field in which the frequency changes with increasing time. On the other hand, since the temporal change of the frequency characteristics of the flow field can be acquired using a wavelet transform, this transform is considered to be effective for analyzing unsteady flow field phenomena, such as the flow field of the torque converter. In the present study, the circulation, which is the total amount of vorticity, are considered. The time-series circulation is calculated from the time-series vorticity results. A wavelet transform is performed to analyze the characteristics of frequency for the circulation. Figure 6 shows the analysis area of the circulation. The analysis area is enclosed by $\mathrm{P}_{A} \mathrm{P}_{\mathrm{B}} \mathrm{P}_{\mathrm{DP}} \mathrm{P}_{\mathrm{C}}$ in Fig. 6. The analysis area is set to the area that covers one stator blade (360/35 degrees $=10.3$ degrees). In this report, the Gabor mother-wavelet that can accurately capture discontinuities, such as the occurrence time of phenomena, is applied. The definition formulas for the wavelet transform function $w_{\psi}(b, a)$ and the mother-wavelet $\psi(t)$ are as follows:

$$
\begin{aligned}
& \psi(t)=\frac{1}{2 \sqrt{\pi} \sigma} \exp \left(-\frac{t^{2}}{\sigma^{2}}\right) \exp (-i t), \\
& w_{\psi}(b, a)=\frac{1}{\sqrt{|a|}} \int_{-\infty}^{\infty} f(t) \overline{\psi\left(-\frac{t-b}{a}\right)} d t,
\end{aligned}
$$

where $a$ is the scale parameter, and $b$ is the translation parameter. In Eqs. (1) and (2), $\sigma$ must be appropriately set in the time and frequency analysis domains ${ }^{(13)}$. In the present paper, the wavelet transform is performed at $\sigma=16$, where both the frequency and time resolution are adequate.

\subsection{Wavelet transform results}

Figures 7 and 8 show the time-series circulation data and the result of the wavelet transform. The gray dotted line in the wavelet transform results indicates the blade passing frequency before and after the transition. The blade passing frequency is estimated from the number of blades of the impeller and turbine, as well as the rotational speed. Figure 7 shows the analysis results for the start-up acceleration pattern. Before and after transition, the blade passing frequency of the impeller changed from 136.7 to $273.3 \mathrm{~Hz}$, while the blade passing frequency of turbine was constant at $6.2 \mathrm{~Hz}$. Figure 8 shows the analysis results for the deceleration pattern. Here, before and after the transition, the frequency of the impeller is constant at $273.3 \mathrm{~Hz}$, while the frequency of the turbine changes from 172.7 to $6.2 \mathrm{~Hz}$. The timeaveraged spectrum for each state is shown on the right-hand side of the wavelet transform result. Several frequencies other than the blade passing frequency are found. Therefore, the flow structure in which several frequencies are superimposed is considered to be complicated. In addition, based on the analysis results of the wavelet transform for the start-up acceleration pattern in Fig. 7, the peak of the spectrum clearly increased linearly from time $1.0 \mathrm{~s}$ to time $2.33 \mathrm{~s}$ in the transition given according to the impeller blade passing frequency. However, for the deceleration pattern in Fig. 8, the changes in the spectrum peak according to the turbine blade passing frequency did not appear clearly in the transition. Since the speed ratio change during the transition is larger in the deceleration pattern compared to that in the start-up acceleration pattern, the structural changes in the flow field are assumed to be more complex and to be caused by the superposition of several frequencies.

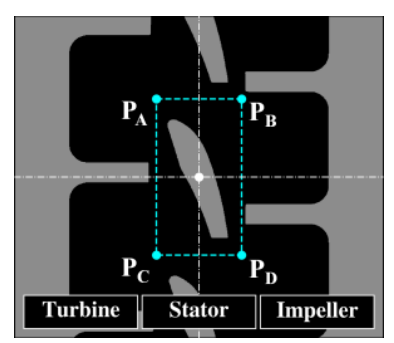

Fig. 6 Calculation area for circulation.

\section{Proper orthogonal decomposition analysis}

\subsection{Proper orthogonal decomposition}

Based on the results of the wavelet transform analysis, the internal flow fields of the torque converter are complicated and have a lot of frequencies superimposed. Therefore, proper orthogonal decomposition (POD) ${ }^{(14)}(15)$ is applied to investigate the structure of the flow field. Proper orthogonal decomposition is a method of decomposing the time-series data of the flow field into several modes to extract the feature structure. Recently, POD has been widely used in numerical simulation and physical experiments.

Assume that the flow field data is as follows:

$$
X=\left[x_{1} x_{2} \cdots x_{N}\right] ., \quad i=1,2, \cdots, N
$$

where $x_{i}$ are the $i$-th time step input vectors, and $N$ is the number of the time step. In the present study, input vectors $x_{i}$ are composed of the flow velocity vectors. The feature structure is obtained as eigenvalues $\lambda_{i}$ and eigenvectors $u_{i}$ by solving the following eigenvalue problem:

$$
X^{T} X u_{i}=\lambda_{i} u_{i}
$$

The POD modes $\Phi$ are obtained as follows:

$$
\phi_{i}=\frac{X u_{i}}{\sqrt{\lambda_{i}}} .
$$

The POD eigenvalues correspond to the contribution of each mode to the total kinetic energy in the observed data. 


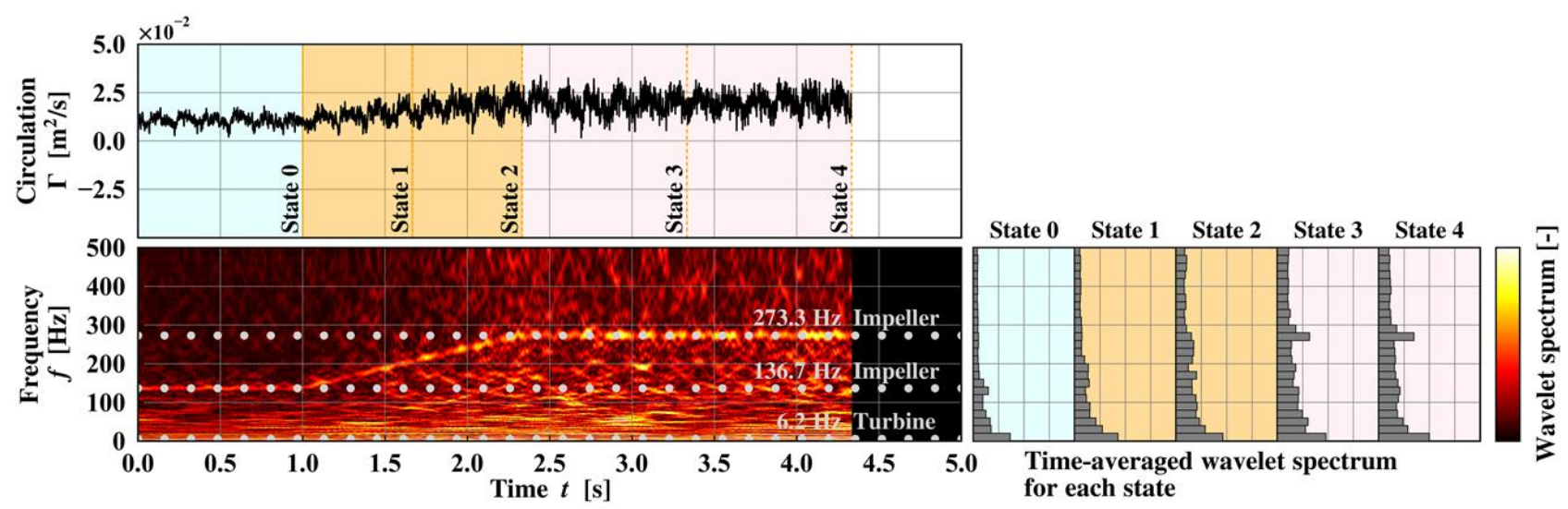

Fig. 7 Time series of circulation, wavelet spectrogram of circulation, and time-averaged wavelet spectrogram for each state under start-up acceleration driving pattern.

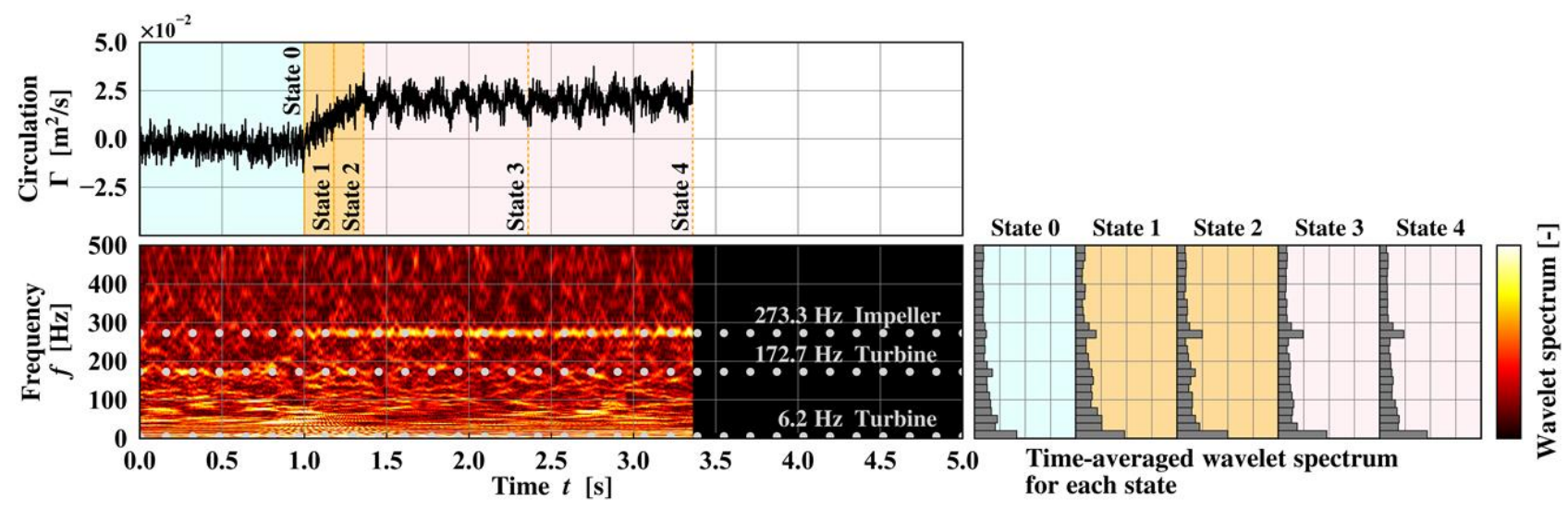

Fig. 8 Time series of circulation, wavelet spectrogram of circulation, and time-averaged wavelet spectrogram for each state under deceleration driving pattern.

\subsection{Proper orthogonal decomposition results}

The eigenvalue of the POD indicates the energy of each mode. The modes are rearranged in descending order of the eigenvalues, and the mode having the largest value is mode 1 . The upper panels of Figs. 9(a) and 9(b) show the distributions of the eigenvalues in each state shown in Table 1, under the start-up acceleration pattern and deceleration pattern, respectively. Each eigenvalue is normalized by the mode- 1 eigenvalue. The lower panels of Figs. 9(a) and 9(b) show the contribution rate and the cumulative contribution rate for each POD mode. In each driving pattern shown in Figs. 9(a) and 9(b), the contribution rates for the first five modes are remarkably larger than those of the other modes. Figures 10(a) and 10(b) show the vorticity contour distributions for the first five modes in each state under the startup acceleration pattern and the deceleration pattern, respectively. As shown in Figs. 10(a) and 10(b), the vorticity distributions are in pairs. This means that the flow is periodic in the time direction (14). However, unpaired vortex structure is observed in each driving pattern, as shown by the broken-line frames in Figs. 10(a) and 10(b). Figure 11 shows the distributions of the velocity vectors and vorticity contour of the POD mode having this unpaired feature. Figure 11(a) shows the distributions of the velocity vectors and vorticity contour under the start-up acceleration pattern. This driving pattern indicates that the rotational speed of the impeller increases. The vector field for the impeller side is uniform in the rotational direction in state 1 at the start time of the transition. In state 2 , in the latter half of the transition, the vortices generated alternately in the clockwise and counterclockwise directions are arranged regularly. In state 3, after the end of the transition, a vortex structure is distinctly observed in the impeller side. The flow structure mainly changes on the impeller side under the start-up acceleration pattern. Figure 11(b) shows the distributions of the velocity vectors and vorticity contour under deceleration. This driving pattern indicates that the rotational speed of the turbine decreases. In state 1 , the vector field near the turbine side is uniform in the counter-rotational direction. In state 2 , the vortices generated alternately in the clockwise and counterclockwise directions are regularly arranged near the turbine side. In state 3 , a vortex structure is observed near the turbine side. The region in which the flow structure changes is large not only on the turbine side but also on the stator side. Based on the above considerations, dynamic cascades, such as those generated by the impeller or turbine with changing rotational speed, induced fluid motion. After transition, the flow structure is gradually reformed according to the speed ratio, such as the clockwise circulation on the positive pressure side of the stator blade in the deceleration pattern, where the speed ratio becomes smaller. In addition, the region in which the flow structure changes is larger under the deceleration pattern than under the start-up acceleration pattern. 

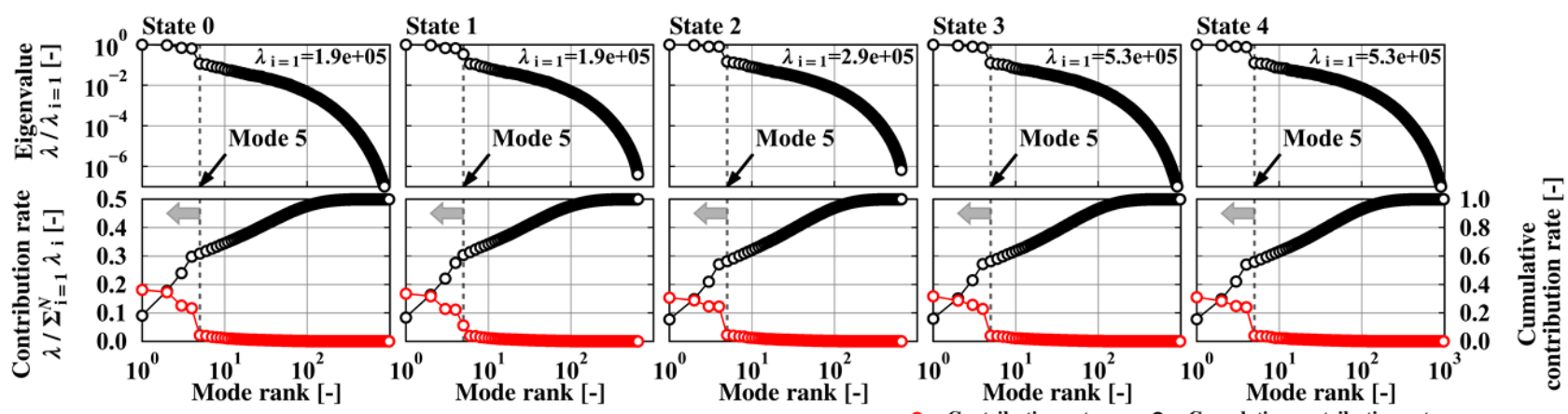

(a) Start-up acceleration driving pattern
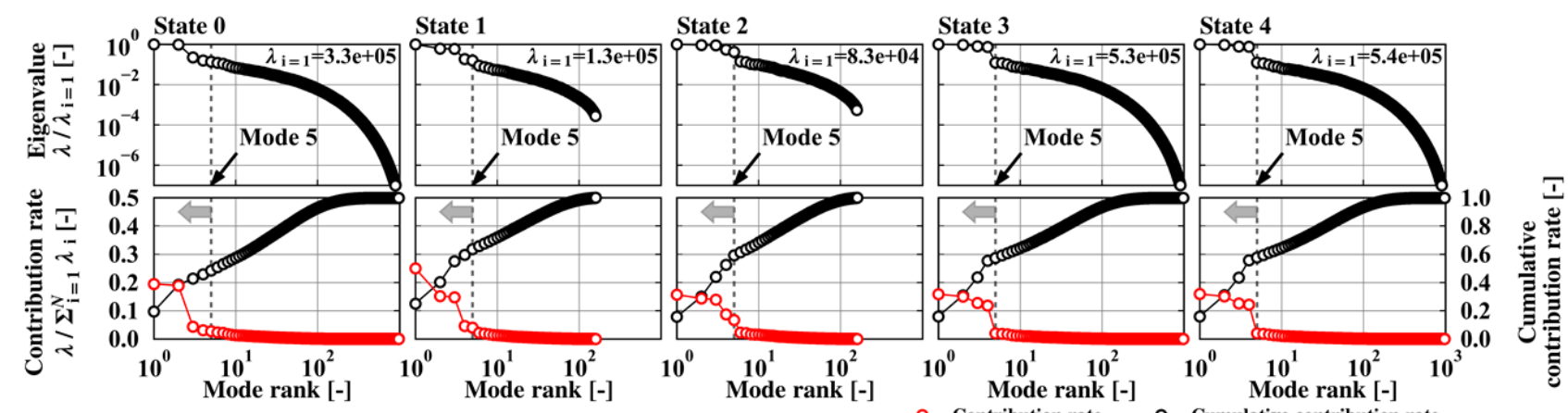

(b) Deceleration driving pattern

Fig. 9 Normalized Eigenvalues, contribution rate, and cumulative contribution rate of each POD mode.

The characteristics of the structural change of the flow field inside the torque converter under the transition condition are successfully extracted using POD and can be clarified and evaluated quantitatively.

\section{Conclusions}

In the present study, the unsteady flow field due to the flow interactions between cascade blades is visualized under the transient driving conditions, and the velocity field is measured using the PIV technique. Proper orthogonal decomposition is applied to the time-series circulation data calculated based on the PIV results. The characteristics of the flow field structure in the torque converter can be extracted and quantitatively evaluated. The following are the results obtained in the present study.

(1) The changes of the flow field structure for the distributions of velocity vectors and vorticity contour in the transition of the torque converter were captured quantitatively to show the difference between the start-up acceleration pattern and the deceleration pattern.

(2) Based on the analysis results of the wavelet transform for the circulation, several frequencies other than the blade passing frequency were found. Since the speed ratio changes are larger in the deceleration pattern than in the start-up acceleration pattern, the structural changes in the flow field were assumed to be more complex and were caused by the superposition of several frequencies.

(3) The dynamic cascades with changing rotational speed induced fluid motion. After transition, the flow structure was gradually reformed according to the speed ratio. The region in which the flow structure changes were larger under the deceleration pattern than the start-up acceleration pattern. The characteristics of the structural change of the flow field in transition were extracted using POD and were able to clarified and evaluated quantitatively.

Proper orthogonal decomposition can be universally used because this analysis method is not dependent on the blade shape or the performance.

\section{References}

(1) Kobayashi, T., Taniguchi, N., Tasaka, T.: Three Dimensional Flow Simulation in a Torque Converter: JSAE IPC-8 Technical Paper, No.9531525 (1995).

(2) Tasaka, T., Oshima, N., Fujimoto, S., Kishi, Y.: Application of Large Eddy Simulation to a Torque Converter to Predict its Fluid Performance: SAE Technical Paper, No.2017-011116 (2017).

(3) L. Sirovich.: Turbulence and the Dynamics of Coherent Structures Part I: Coherent Structures: Quarterly of Applied Mathematics, 45, pp.561-571 (1987).

(4) L. Sirovich.: Turbulence and the Dynamics of Coherent Structures Part II: Symmetries and Transformations: Quarterly of Applied Mathematics, 45, pp.573-582 (1987).

(5) L. Sirovich.: Turbulence and the Dynamics of Coherent Structures Part III: Dynamics and Scaling: Quarterly of Applied Mathematics, 45, pp.583-590 (1987).

(6) Wei, W., Huang, M., Li, Y., Yan, Q.: Flow Pattern Evolution and Energy Decomposition of Flows at Different Operating Conditions in a Hydrodynamic Torque Converter: 
Proceedings of ASME Turbo Expo 2016, GT2016-56874 (2016).

(7) Yan, Q., Huang, M., Wei, W.: Analysis of Energy Loss Mechanism at the Speed Ratio of Design Operating Condition in Hydrodynamic Torque Converters: Proceedings of the ASME 2016, IMECE2016-67613 (2016).

(8) Kawasaki, K., Okada, K., Nishino, K.: Dynamic stereo PIV measurements and 3-D reconstruction of the flow field inside a torque converter model: JSME Fluids Engineering Conference, Vol.2015, 1619 (2015).

(9) Kunisaki, Y., Murata, S., Tanaka, Y., Takeda, T.

: Experimental Analysis for Internal Flow Field of Torque Converter - Application of wavelet analysis to flow field between cascades -: TVSJ, Vol.39, No.5, pp.11-18 (2019).

(10) The Visualization Society of Japan.: PIV Handbook: Morikita Publishing Co., Ltd., pp.69-75 (2002).

(11) Hart, D. P.: PIV error correction: Experiments in Fluids, Vol.29, Issue 1, pp.13-22 (2000).

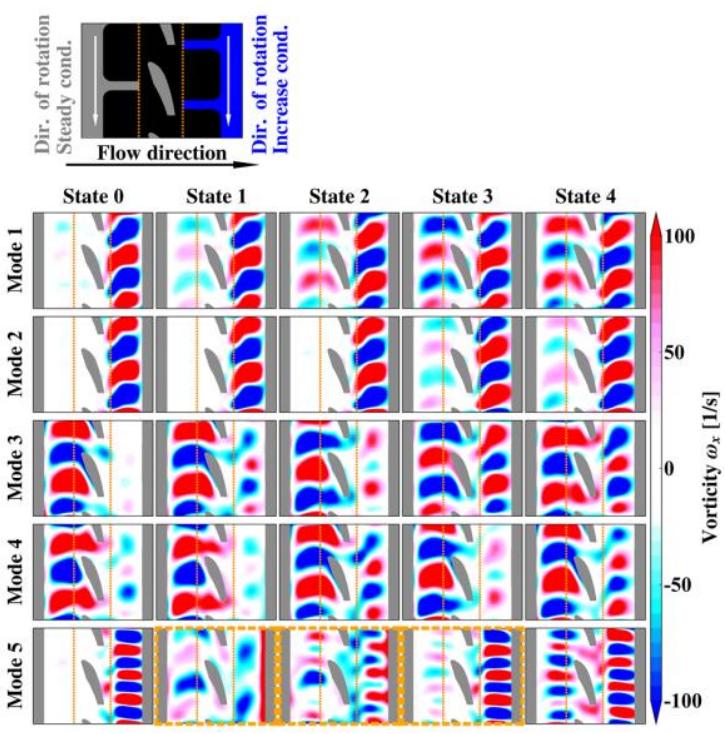

(a) Start-up acceleration driving pattern
(12) Dong, Y., Lakshminarayana, B., Maddock, D.: Steady and Unsteady Flow Field at Pump and Turbine Exits of a Torque Converter: Journal of Fluids Engineering, 120-3, pp.538-548 (1998).

(13) Michihira, M., Oe, T., Hisayama, K., Amako, K., Tsuyoshi, A.: Application of Time-Frequency Analysis for Power Electronics: JIPE, Vol. 29, No.2, pp.8-14 (2004). (in Japanese)

(14) Taira, K.: Proper Orthogonal Decomposition in Fluid Flow Analysis:1. Introduction: Journal of Japan Society of Fluid Mechanics (Nagare), Vol. 30, No. 2, pp. 115-123 (2011). (in Japanese).

(15) Taira, K.: Proper Orthogonal Decomposition in Fluid Flow Analysis:2. Applications: Journal of Japan Society of Fluid Mechanics (Nagare), Vol. 30, No. 3, pp. 263-271 (2011). (in Japanese).

Fig. 10 Vorticity contour distributions of each state in first five POD modes.
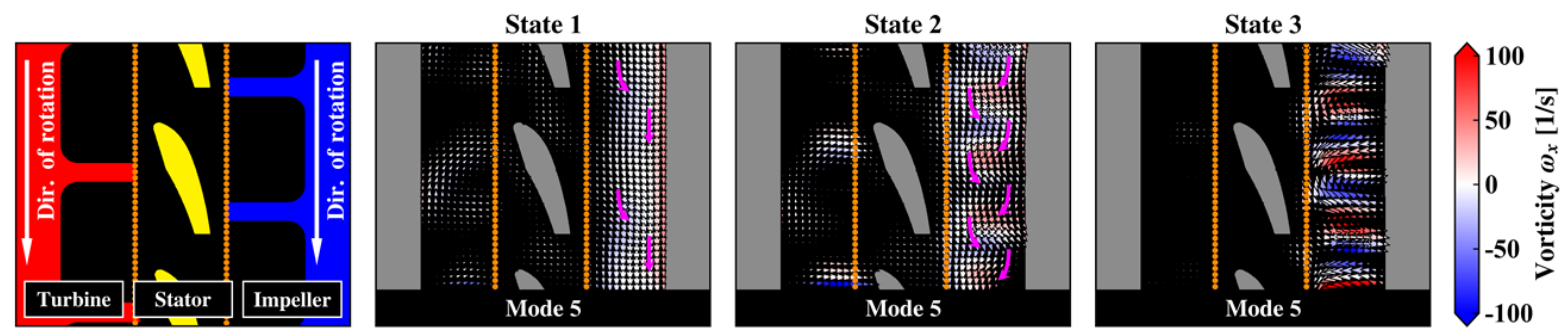

(a) Start-up acceleration driving pattern
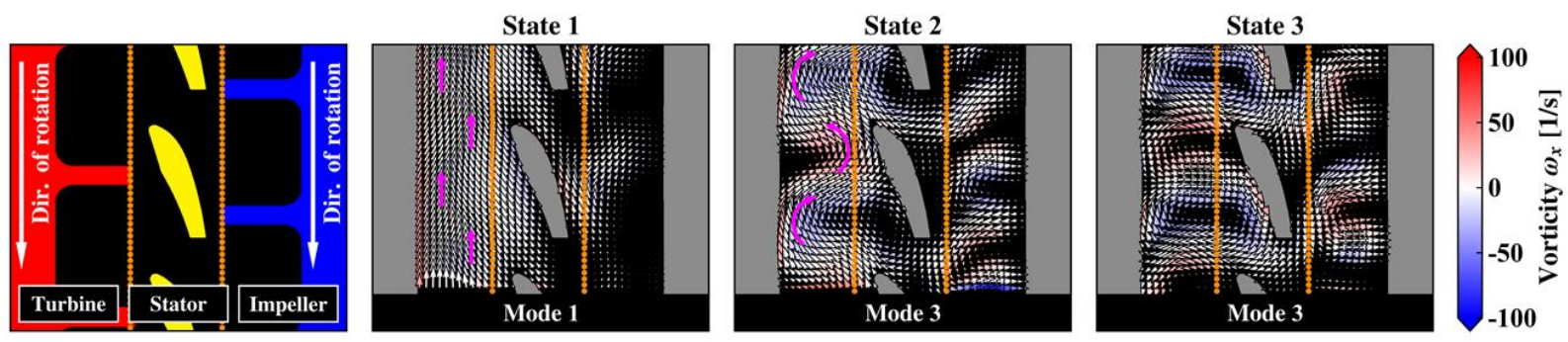

(b) Deceleration driving pattern

Fig. 11 Distributions of velocity vectors and vorticity contour with features. 